\title{
Low-Grade Extranodal Marginal Zone B Cell Lymphoma of Malt in the Kidney
}

\author{
Yoon Kyung Jeon ${ }^{1}$ and Ja Hyeon $\mathrm{Ku}^{*}, 2$ \\ ${ }^{I}$ Department of Pathology, Seoul National University College of Medicine, Seoul, Korea \\ ${ }^{2}$ Department of Urology, Seoul National University College of Medicine, Seoul, Korea
}

\begin{abstract}
Primary renal lymphomas are very rare since renal involvement by the disease is most often a manifestation of disseminated disease. We report an 88-year-old man with low-grade extranodal marginal zone B cell lymphoma of mucosa-associated lymphoid tissue (MALT) (MALT lymphoma) arising in the kidney. After the workup, the patient was thought to have renal cell carcinoma and underwent partial nephrectomy. The pathologic evaluation showed a MALT lymphoma. No additional treatment was given, and the patient was disease free during the follow-up.
\end{abstract}

Keywords: Low-grade MALT lymphoma, kidney.

\section{CASE REPORT}

An 88-year-old man with a history of diabetes was presented with right flank pain. At another institution, he was diagnosed with right proximal ureter stone, and was transferred to our hospital for additional examination and treatment. At admission, a physical examination showed tenderness of right costovertebral angle. Palpable lymphadenopathy or edema was absent. Neurological, cardiovascular, and respiratory system examinations were normal. Computed tomography of the abdomen disclosed a $3.1 \times 2.2 \mathrm{~cm}$ sized enhancing right kidney tumor arising from the lower pole without retroperitoneal lymph node involvement, as well as hydronephrosis due to radio-opaque density in the proximal ureter (Fig. 1). Chest radiography was normal.

With a presumptive diagnosis of a papillary type renal cell carcinoma, the patient underwent right partial nephrectomy. And then, ureteroscopy was performed but no detectable stone was found at ureteroscopy. A double $\mathrm{J}$ stent was placed in the right side. Follow-up non-contrastenhanced CT on postoperative day 2 confirmed the absence of stone and a well-positioned stent. The double J stent was removed.

Grossly, the mass involved peri-nephric fat and renal parenchyma with ill-defined border. It measured $2.7 \times 2 \times$ $1.5 \mathrm{~cm}$ in size and had solid firm consistency with white-tan color. Microscopic examination showed diffused proliferation of small lymphoid cells and scattered lymphoid follicles (Fig. 2A). The lymphoid cells infiltrated in a diffused pattern or around the reactive lymphoid follicles. Occasionally, the small lymphoid cells permeated into the reactive lymphoid follicles, thereby, formed so-called follicular colonization (Fig. 2B). The lymphoid cells actively

*Address correspondence to this author at the Department of Urology, Seoul National University Hospital, 28, Yongon Dong, Jongno Ku, Seoul 110744, Korea; Tel: 82-2-2072-0361; Fax: 82-2-742-4665;

E-mail: randyku@hanmail.net, kuuro70@snu.ac.kr infiltrated between renal tubules and glomeruli, however, they did not directly invaded into the epithelium. Therefore, lymphoepithelial lesion was not evident. Tumor cells were predominantly composed of small lymphoid cells with condensed chromatin, regular or slightly irregular nuclear membrane, indistinct nucleoli, and scanty cytoplasm. Sheets of monocytoid cells with small amount of pale cytoplasm were occasionally observed. There were scattered large immunoblastic cells and plasma cells. Mitotic figures were rare, and proliferation center was absent. Immunohistochemical staining was performed on formalinfixed paraffin-embedded tissue sections using the TechMate тм 500 Plus (DAKO, Glostrup, Denmark) according to the manufacturer's protocol based on the labeled streptavidinbiotin-peroxidase method. The primary antibody used were as follows: CD20, CD3, CD5, bcl-2, Ki-67 (DAKO, Glostrup, Denmark), CD10, cytokeratin (Novocastra, Newcastle, UK), CD23, cyclin D1 (Labvision, Fremont, CA), and bcl-6 (Santa cruz, Santa Cruz, CA). The tumor cells were positive for CD20 and bcl-2, and negative for CD3, CD5, cyclin D1, and CD23 (Fig. 2C). The Ki-67 proliferation index was very low with approximately $1 \%$ of tumor cells. CD10 and bcl-6 were positive in the germinal centers of reactive lymphoid follicles. CD23 immunostaining for follicular dendritic cells in the germinal center demonstrated colonization of lymphoid follicle by CD20postive small lymphoid cells (Fig. 2D). Based on the preceding histopathologic and immunohistochemical features, the tumor was diagnosed as low-grade extranodal marginal zone B cell lymphoma of Mucosa-associated lymphoid tissue (MALT).

Additional postoperative staging, including bone marrow biopsy, thoracic computed tomography, and PET, was negative. After a multidisciplinary team discussion, the patient opted for observation. The patient remained free clinically from disease.

\section{DISCUSSION}

MALT lymphomas are in the group of marginal zone Bcell lymphomas and have recently been recognized as a 


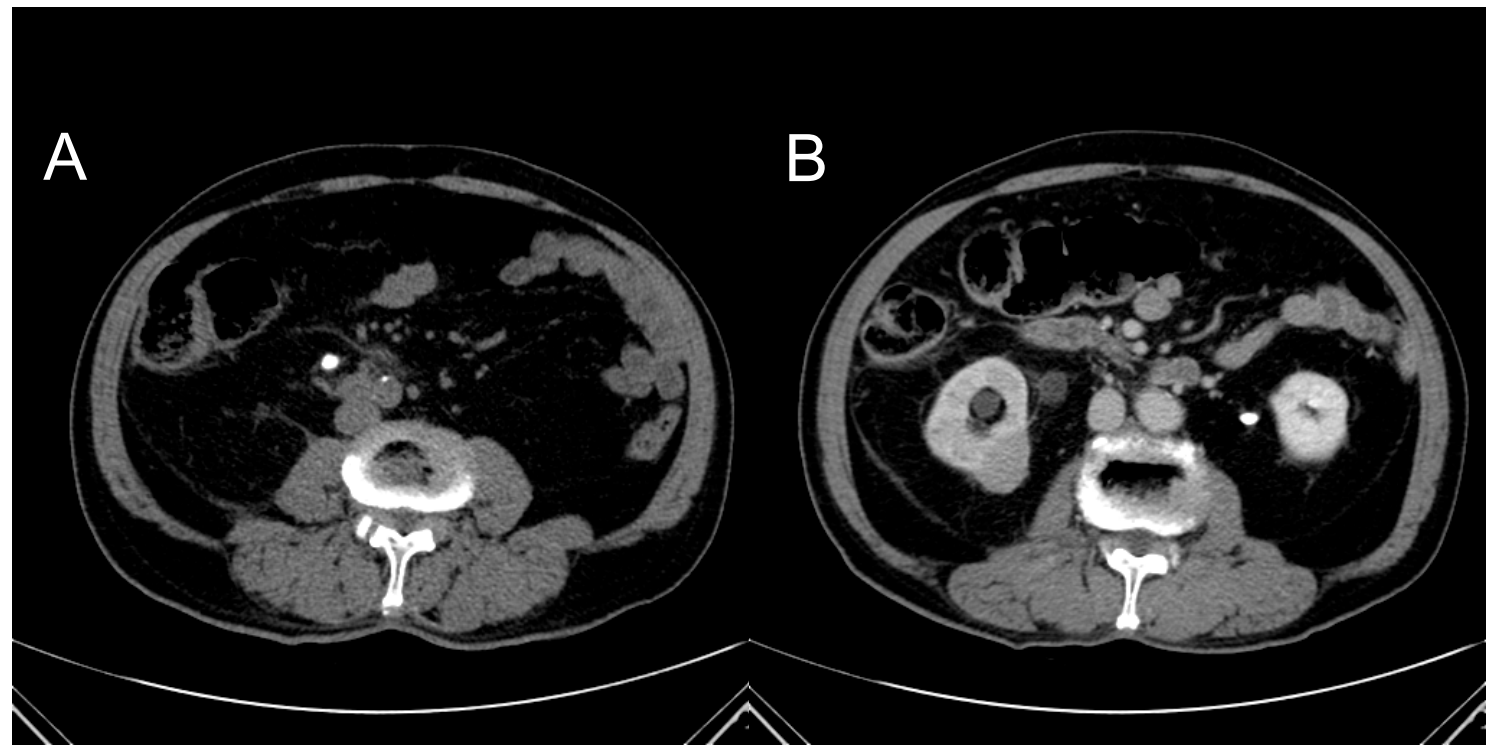

Fig. (1). Computed tomography of renal lymphoma. (A) Right renal mass arising from the lower pole. (B) Radio-opaque density in the right proximal ureter.
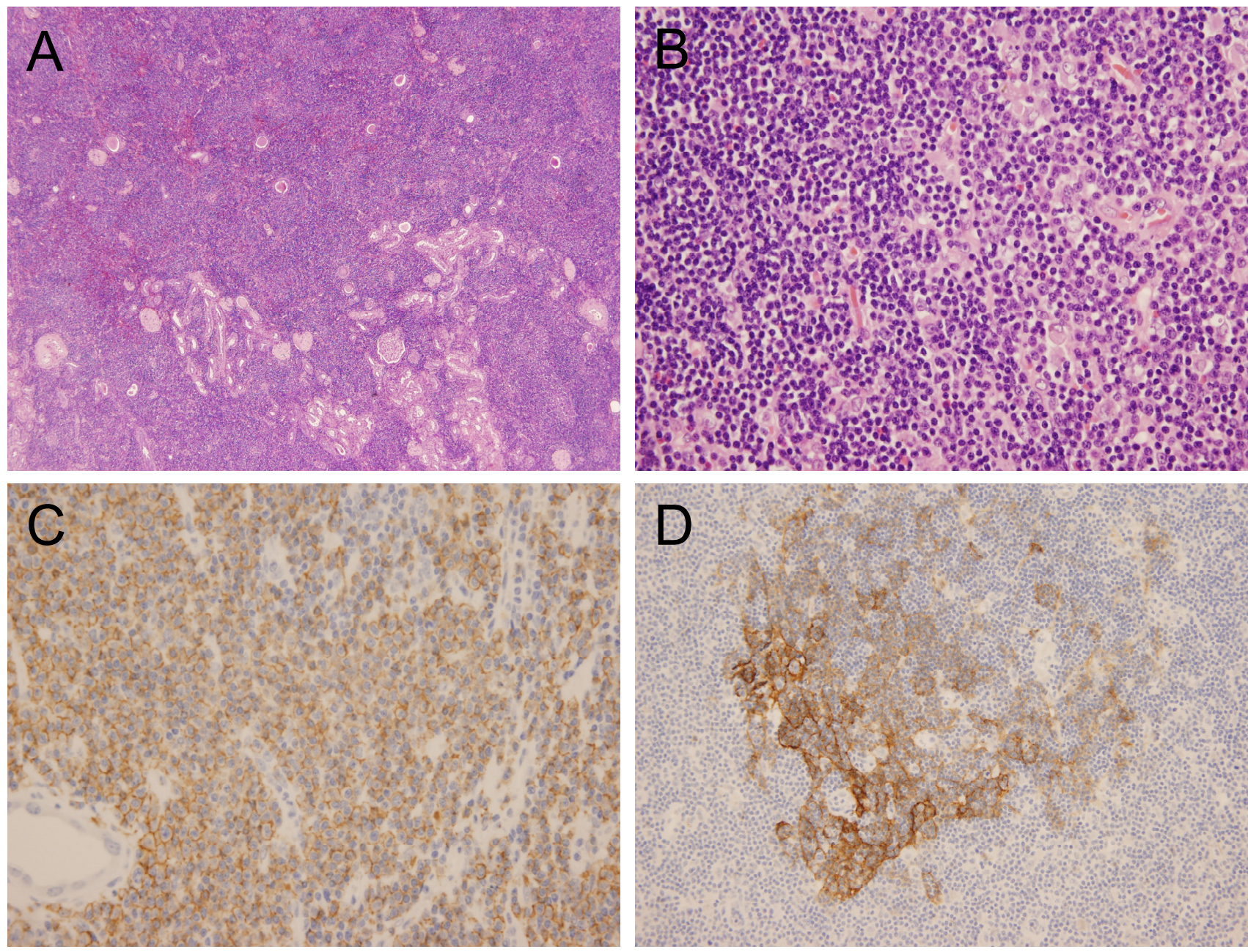

Fig. (2). Pathologic features of tumor. (A) The tumor was composed of dense lymphoid cells proliferating in a diffuse pattern or around the reactive lymphoid follicles. The lymphoid cells infiltrated between renal tubules and glomeruli (Hematoxylin and Eosin, original magnification x40). (B) Most of the neoplastic lymphoid cells were small-sized and had scanty cytoplasm (left field). Occasionally, they showed monocytoid differentiation with small amount of pale cytoplasm (right field) (Hematoxylin and Eosin, original magnification $\mathrm{x} 400$ ). (C) Tumor cells were positive for CD20 in immunohistochemistry (Original magnification x400). (D) CD23 immunostaining revealed network of follicular dendritic cells in the germinal center of reactive lymphoid follicle, which was colonized by small lymphoid cells (Original magnification $\mathrm{x} 400$ ). 
distinctive form of malignant lymphoma [1]. The term MALT lymphoma represents a marginal zone B cell lymphoma arising in extranodal tissues, in which lymphoid tissues are not usually present [1]. Although renal involvement in any type of lymphoma is common, lymphomas of MALT arising in renal tissue is extremely rare. Only a few cases of primary renal MALT lymphoma have been reported in the literature [2-9]. In contrast to other type of low-grade lymphoma, these tumors have a tendency to be localized at diagnosis and to be curable with local therapy [6]. The diagnosis of primary renal MALT lymphoma presenting as a solitary mass usually requires radical nephrectomy since the differential diagnosis from renal cell carcinoma may not be made with current imaging studies.

MALT lymphoma of the kidney may be the result of systemic involvement. Half of renal MALT lymphoma has been described in association with MALT lymphoma at other sites [8]. Table 1 summarized cases of localized renal MALT lymphoma reported in the literature. The initial example of primary localized renal MALT lymphoma was described by Colovic et al. [2]. The patient was disease free after radical nephrectomy without additional treatment. Jindal et al. [4] reported another case of low grade MALT lymphoma of the kidney that had very indolent behavior. The patient remained asymptomatic during a period of 13 years. Stokes et al. [5] reported 2 cases with the novel renal biopsy findings of coexistent renal MALT lymphoma and membranoproliferative glomerulonephritis. Laven et al. [7] reported a patient with a Bosniak type II renal cyst associated with MALT lymphoma in the cyst wall. The patient's clinical course without chemotherapy was consistent with natural history of renal MALT lymphoma.
Qui et al. [8] demonstrated two cases of primary renal MALT lymphoma; the first patient received chemotherapy without complications, and the second patient underwent a partial nephrectomy and was asymptomatic at the subsequent follow-up. Recently, Garcia et al. [9] described 10 cases of kidney MALT lymphoma, including 6 localized cases. This was the largest group of localized renal MALT lymphomas reported. They suggested that MALT lymphoma localized to the kidney share pathogenetic similarities with MALT lymphomas arising at other anatomic sites, at least in a subset of cases.

We described the second case reported in the medical literature of a renal MALT lymphoma treated by a partial nephrectomy. Although the majority of the primary renal lymphomas are of high grade with an aggressive behavior, renal involvement of MALT lymphoma may be clinically silent. In our case, tumor was found incidentally by computed tomography during a work-up for a ureter stone. Our case illustrated the difficulty in the preoperative diagnosis of small lymphoma because there are no specific findings on either radiographic or blood examinations. Although kidney biopsy is the most expeditious and direct way to establish the underlying diagnosis of renal masses, it is generally accepted that a specific diagnosis is not essential for the initial management of a renal mass since the recommended procedure is total or partial nephrectomy to achieve therapeutic and diagnostic goals. The present case further suggests that small renal MALT lymphoma can be managed with optimistic results using partial nephrectomy alone. However, the disease may relapse after years, longer follow-up is necessary before suggesting that partial nephrectomy alone can cure small localized renal MALT lymphoma.

Table 1. Summary of Primary Renal Mucosa-Associated Lymphoid Tissue Lymphoma

\begin{tabular}{|c|c|c|c|c|c|}
\hline & Sex/Age (yr) & Side & Associated Diseases & Treatment & Follow-Up \\
\hline Colovic et al. [2] & $\mathrm{M} / 50$ & Right & Helicobacter pylori gastritis & Nephrectomy & NA \\
\hline Mhawech et al. [3] & $\mathrm{F} / 76$ & Right & None & Nephrectomy & NA \\
\hline Jindal et al. [4] & $\mathrm{M} / 45$ & Left & None & Nephrectomy; chemotherapy & Alive with disease at $13 y$ \\
\hline \multirow[t]{2}{*}{ Stokes et al. [5] } & $\mathrm{F} / 68$ & NA & MPGN & Prednisone & NA \\
\hline & $\mathrm{F} / 72$ & NA & MPGN & Prednisone & Alive with disease at $6 \mathrm{mo}$ \\
\hline Tuzel et al. [6] & $\mathrm{M} / 43$ & Right & None & Nephrectomy & Disease free at $28 \mathrm{mo}$ \\
\hline Laven et al. [7] & $\mathrm{M} / 51$ & Left & Renal cyst & Laparoscopic renal exploration & Alive with disease at $12 \mathrm{mo}$ \\
\hline \multirow[t]{2}{*}{ Qui et al. [8] } & $\mathrm{F} / 83$ & Left & None & Chemotherapy & Disease free at 8 no \\
\hline & $\mathrm{M} / 53$ & Left & Sarcoidosis & Partial nephrectomy & Disease free at $10 \mathrm{mo}$ \\
\hline \multirow[t]{6}{*}{ Garcia et al. [9] } & $\mathrm{F} / 77$ & NA & None & NA & Disease free at $36 \mathrm{mo}$ \\
\hline & $\mathrm{M} / 65$ & Right & Renal actinomycosis & Antibiotics & Disease free at 14 mo \\
\hline & $\mathrm{M} / 54$ & Left & None & Chemotherapy & Disease free at $36 \mathrm{mo}$ \\
\hline & $\mathrm{F} / 75$ & Right & TCC, bladder & Nephrectomy; chemotherapy & Disease free at $12 \mathrm{mo}$ \\
\hline & $\mathrm{M} / 66$ & Left & Subsequent RCC, Rt & Nephrectomy & Disease free at $53 \mathrm{mo}$ \\
\hline & $\mathrm{M} / 83$ & Right & None & Chemotherapy & Disease free at $9 \mathrm{mo}$ \\
\hline Current case & $\mathrm{M} / 88$ & Right & Diabetes, ureter stone & Partial nephrectomy & Disease free at $6 \mathrm{mo}$ \\
\hline
\end{tabular}

NA, not available; MPGN, membranoproliferative glomerulonephritis; TCC, transitional cell carcinoma; RCC, renal cell carcinoma. 


\section{REFERENCES}

[1] Banks PM, Issacson PG. MALT lymphomas in 1997: where do we stand? Am J Clin Pathol 1999; 111(suppl 1): S75-83.

[2] Colovic M, Hadzi-Djokic J, Cemerikic V, Colovic R, Jankovic G, Dacic M. Primary MALT lymphoma of the kidney. Hematol Cell Ther 1999; 41: 229-32.

[3] Mhawech P, Ahearn J, Medeiros LJ. Pathologic quiz case: a unilateral renal mass in an elderly woman. Arch Pahol Lab Med 2000; 124: 919-20.

[4] Jindal B, Sharma SC, Das A, Banerjee AK. Indolent behavior of low grade B-cell lymphoma of mucosa associated lymphoid tissue arising in the kidney. Urol Int 2001; 67: 91-3.

[5] Stokes MB, Wood B, Alpers CE. Membranoproliferative glomerulonephritis associated with low-grade B cell lymphoma presenting in the kidney. Clin Nephrol 2002; 57: 303-9.
[6] Tuzel E, Mungan MU, Yorukoglu K, Basakci A, Kirkali Z. Primary renal lymphoma of mucosa-associated lymphoid tissue. Urology 2003; 61: 463xviii-xx.

[7] Laven BA, Orvieto MA, Rapp DE, et al. Malignant B-cell lymphoma in renal cyst wall. Urology 2004; 69: 590.e28-590.e29.

[8] Qui L, Unger PD, Dillon RW, Strauchen JA. Low-grade mucosaassociated lymphoid tissue lymphoma involving the kidney: report of 3 cases and review of the literature. Arch Pathol Lab Med 2006; 130: 86-9.

[9] Garcia M, Konoplev S, Morosan C, Abruzzo LV, Bueso-Ramos CE, Medeiros LJ. MALT lymphoma involving the kidney: a report of 10 cases and review of the literature. Am J Clin Pathol 2007; 128: 464-73.

Received: August 4, 2009

Revised: August 21, 2009

Accepted: August 22, 2009

(C) Jeon and $\mathrm{Ku}$; Licensee Bentham Open.

This is an open access article licensed under the terms of the Creative Commons Attribution Non-Commercial License (http://creativecommons.org/licenses/by$\mathrm{nc} / 3.0 /$ ) which permits unrestricted, non-commercial use, distribution and reproduction in any medium, provided the work is properly cited. 